\title{
Research on Basic Characteristics and Bidding Strategy of Thermal Power Units in Fujian Spot Market
}

\author{
Yuhui Song ${ }^{1, *}$, Zhanhua Pan $^{1}$, Baike Chen ${ }^{1}$, and Zhaoxia Jing ${ }^{1}$ \\ ${ }^{1}$ South China University of Technology, School of Electric Power, Guangzhou, China
}

\begin{abstract}
In the electricity market environment, thermal power units have changed from the executors of power production under the monopoly mechanism to the decision-makers of production and operation under the competitive environment. The merits and demerits of bidding schemes for thermal power units are directly related to self-interest of themselves. The bidding decisions of power plants are not only affected by economic factors, but also by technical factors peculiar to the power system and the electric generator. In recent years, research on bidding strategies of thermal power units based on the power market environment has been paid more and more attention in the field of electric market. This paper first introduces the basic peak regulation and frequency modulation technical characteristics of thermal power units and cost calculation. Then, from the angle of quotation, paper analyzes characteristics of quotation mechanism of units in Fujian Electric Power day-ahead, real-time and peak regulation auxiliary service market. Furthermore, the research status of bidding strategies of thermal power units participating in electricity market at home and abroad in cost analysis, market clearing price prediction, game theory and so on are summarized. Finally, the bidding strategy for units in Fujian Spot Market is put forward.
\end{abstract}

\section{Introduction}

In August 2019, National Development and Reform Commission (NDRC) and State Energy Administration jointly issued "Opinions on deepening the construction pilot work of power spot market" [1], signifying that construction of spot market for electric power in China is entering the stage of further promotion. Fujian province, as the first batch of 8 pilot provinces of spot market construction, is promoting transformation of electric power production from planned operation mode to market economy operation mode. With the gradual marketization of energy and ancillary services in Fujian province, the profit model and decision-making basis of thermal power units will change greatly. In recent years, research on technical and cost characteristics of thermal power units has become a research hotspot and has emerged a large number of literature. However, there is no literature that summarizes basic characteristics, peak regulation (PR) and frequency modulation (FM) characteristics, also energy consumption cost in terms of methodology. There is also no relevant research on specific analysis of bidding strategies of thermal power units in the Fujian Spot Market Environment.

With development of economy and power industry, power grid and electric generators in China have also experienced major changes and improvements. Compared with hydro power units, thermal power units have characteristics of short construction period and flexible layout, so in late 1990s, under social situations, thermal power units have been fully developed because of characteristics of economic growth in China. However, due to the severe challenge of global environmental protection caused by rapid increase of greenhouse gas emission resulted from industrial development and economic growth, international energy saving and emission reduction needs have been put on the agenda. Under the environment protection framework of "Blue Sky Defense War" in China, electric power system is undergoing great changes according to the national unified deployment and energy policy of "Saving, clean and safe". A large number of new energy generating units are supported to connect to power grid by policy, so new energy generation and characteristics of China's power grid structure have cast increasing peak-valley difference of power grid. At present, the capacity of thermal power units in China still accounts for the majority of generating capacity. If new energy power industries are integrated into power grid on a large scale, the peak-shaving tasks will be increased mainly by thermal power units. Based on above-mentioned background, it is imperative to explore the PR and FM characteristics of thermal power units. Under the background of promotion of spot market of Fujian Electric Power and the perfection of system of FM and PR in Fujian, the unit itself needs to ensure the unity of economy and safety. Therefore, it is very important to analyze the cost characteristics of thermal power units. At the same time, it is necessary to analyze how to make thermal power units participate in spot market quotation to obtain the highest profit.

\footnotetext{
* Corresponding author: 897917967@qq.com
} 
This paper systematically introduces the technical and cost characteristics of thermal power units. Then, based on analysis of bidding mechanism of Fujian electric power market for day-ahead, real-time balance and PR ancillary services, this paper summarizes the research status of bidding strategies of thermal power units participating in electricity market at home and abroad, and puts forward bidding strategies of units suitable for Fujian spot market. The thesis is divided into five parts. The first part is the introduction; the second part introduces the PR and FM characteristics of thermal power units and the calculation method of unit cost; the bidding mechanism of thermal power units in Fujian electric power day-ahead market, real-time balance market and PR ancillary service market is analyzed in the third part; the fourth part summarizes six bidding strategies containing cost analysis, market clearing price prediction and game theory, and put forward unit bidding methods suitable for Fujian spot market; the fifth part is conclusion.

In this paper, the characteristics of thermal power unit analysis, bidding strategies and application in Fujian power market conducted a preliminary summary and research work. However, there is still much work to be further studied in the future, such as more effective bidding methods, collusion among multiple market entities, simulation of corresponding market rules and bidding strategy analysis and so on. At the same time, as thermal power units participating in the market have different game strategies and goals, game behaviors in the actual market is more complicated. How to analyze and discuss the factors that influence bidding game behaviors and choices of bidding strategies in the real market is worth further study.

\section{Basic Characteristic Analysis of Thermal Power Units}

\subsection{Analysis of basic technical characteristics of thermal power units}

Since the reform and opening-up, China's thermal power generation has developed rapidly. As support of power grid, thermal power units' basic characteristics are mainly reflected in short construction period, flexible layout, high fuel cost, high operating cost, environmental impacts and so on. Under the background of the development of spot market and clean energy consumption in Fujian province, the demand of PR and FM for fossil-fired power units of the society and new energy enterprises is increasing [2]. When thermal power units participate in auxiliary service market, main parameters include response time, duration, regulation range, regulation direction and so on (details in Table1).

Table 1. Important parameters of thermal power units participating in ancillary service market.

\begin{tabular}{|c|c|c|}
\hline Parameter name & Definition & Characteristic \\
\hline Response time & $\begin{array}{c}\text { maximum time unit takes to receive a } \\
\text { scheduling instruction to fully meet its } \\
\text { requirements }\end{array}$ & $\begin{array}{c}\text { From the second level of inertia response, primary } \\
\text { FM, secondary FM, minutes level of rotation } \\
\text { reserve, to non-rotation reserve response, time } \\
\text { requirements gradually extended. }\end{array}$ \\
\hline Duration & $\begin{array}{c}\text { minimum time that standby resource needs } \\
\text { to remain in this state after it has fully } \\
\text { responded to the scheduling instructions }\end{array}$ & $\begin{array}{c}\text { 1) Short duration requirements for intermittent } \\
\text { renewable energy output and system FM; } \\
\text { 2) For long-term fluctuations in renewable energy, } \\
\text { especially during rising and falling periods of } \\
\text { photovoltaic power generation, a long-lasting and } \\
\text { flexible ramp-up resource is required. }\end{array}$ \\
\hline Amplitude of adjustment & $\begin{array}{c}\text { relative to the maximum offset that can be } \\
\text { achieved by current operation point, } \\
\text { embodied in the secondary service capacity } \\
\text { requirements to meet certain reliability } \\
\text { standards }\end{array}$ & $\begin{array}{c}\text { FM and standby services responding to accidents } \\
\text { and disturbances require much less amplitude } \\
\text { modulation than the flexible ramp service. }\end{array}$ \\
\hline Regulation direction & $\begin{array}{c}\text { 1) The direction of regulation can reflect } \\
\text { relative position of adjustment capacity } \\
\text { relative to the operating base point } \\
\text { adjustment range, as shown in Figure 1 }\end{array}$ & $\begin{array}{c}\text { willingness of market participants to generate } \\
\text { electricity, for example, market members who } \\
\text { wish to obtain more generator opportunities will } \\
\text { choose to participate only in the upward } \\
\text { regulation; }\end{array}$ \\
$\begin{array}{c}\text { 2) Flexible resources that are adaptable to only } \\
\text { one-way regulation, such as wind turbines that } \\
\text { temporarily reduce capacity or demand-side } \\
\text { resources that can only reduce the load. }\end{array}$ \\
\hline
\end{tabular}




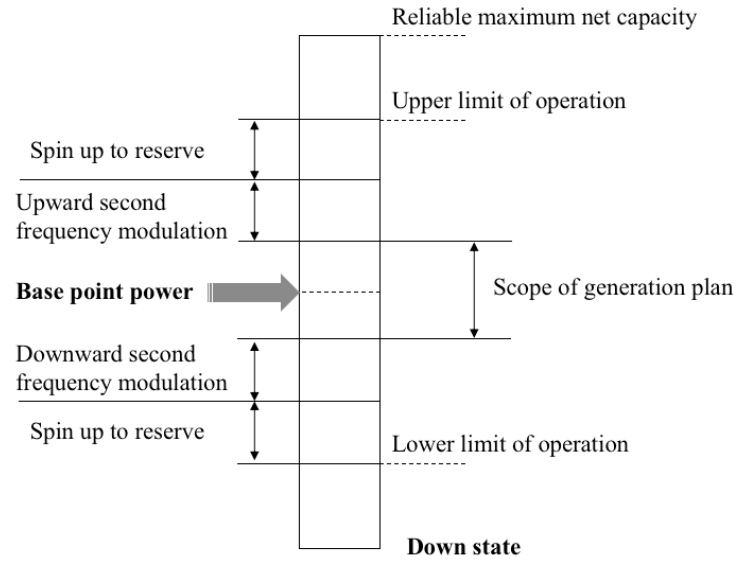

Fig. 1. Relationship between adjustment directions and electric generating capacity
According to the relationship between electric generating capacity and regulation direction in Fig. 1, between the minimum and maximum output of generating units, there are several types in the auxiliary service market such as secondary FM, rotary reserve and non-rotary reserve.

\subsubsection{Analysis of peak regulation characteristics of thermal power units}

At present, there are many peak-load regulation methods for thermal power units in China, and can be generally divided into four categories: starting and stopping two shifts, low-speed rotating heat reserve, low-steam noload and low-load PR.

Table 2. Summary and comparative analysis of PR modes of thermal power units

\begin{tabular}{|c|c|c|c|}
\hline PR mode & Characteristic & Merits & Faults \\
\hline $\begin{array}{l}\text { Starting and } \\
\text { stopping two } \\
\text { shifts }\end{array}$ & $\begin{array}{c}\text { Apply to the more day load, less } \\
\text { night load }\end{array}$ & $\begin{array}{l}\text { It can meet demand of large peak } \\
\text { load regulation. The peak load } \\
\text { regulation capacity of the unit is } \\
\text { large, and can reach } 100 \% .\end{array}$ & $\begin{array}{c}\text { Due to frequent start-stop } \\
\text { operation and effect of } \\
\text { alternating stress, the creeping } \\
\text { loss and low cycle fatigue of unit } \\
\text { will increase greatly, and the life } \\
\text { of rotor will be shortened } \\
\text { obviously. }\end{array}$ \\
\hline $\begin{array}{l}\text { Low-speed } \\
\text { rotating heat } \\
\text { reserve }\end{array}$ & $\begin{array}{l}\text { The load of the steam turbine is } \\
\text { reduced to } 0 \text {, which is separated } \\
\text { from the power grid, and the } \\
\text { steam is injected into the steam } \\
\text { turbine through fuel combustion } \\
\text { to keep the unit in the state of } \\
\text { low speed rotation and high } \\
\text { temperature }\end{array}$ & $\begin{array}{l}\text { The safety is higher, and the } \\
\text { operation is simple. }\end{array}$ & $\begin{array}{l}\text { When this method is used, } \\
\text { special person must be sent to } \\
\text { monitor the unit in real time }\end{array}$ \\
\hline $\begin{array}{c}\text { No load PR } \\
\text { with less steam }\end{array}$ & $\begin{array}{l}\text { When this method is used, the } \\
\text { unit operates normally in the } \\
\text { daytime and zero-load operation } \\
\text { in the evening under low-load } \\
\text { stage. At the same time, a small } \\
\text { amount of power is absorbed } \\
\text { from the power grid to achieve } \\
\text { the goal of maintaining the unit } \\
\text { at rated speed. }\end{array}$ & $\begin{array}{l}\text { Life loss is small, and the } \\
\text { method saves starting time of the } \\
\text { unit. }\end{array}$ & $\begin{array}{l}\text { This mode requires high } \\
\text { performance of units. Most of } \\
\text { the units installed in China do } \\
\text { not have conditions to use this } \\
\text { mode. }\end{array}$ \\
\hline Low-load PR & $\begin{array}{l}\text { The load of units is regulated by } \\
\text { three operation modes: constant } \\
\text { voltage, variable voltage and } \\
\text { mixed variable voltage.the } \\
\text { demand of peak load regulation }\end{array}$ & $\begin{array}{l}\text { safety, good mobility, and less } \\
\text { operation }\end{array}$ & $\begin{array}{l}\text { Considering the unit economy, it } \\
\text { is not easy to operate in this } \\
\text { mode for a long time. }\end{array}$ \\
\hline
\end{tabular}

\subsubsection{Analysis of frequency modulation characteristics of thermal power units}

The FM market is oriented to the secondary FM service, which requires electric generators to automatically track the orders issued by the dispatching organization through Automatic Generation Control (AGC) devices, and to adjust the power output in real time according to a certain regulation rate to meet power system frequency and Area Control Error (ACE) requirements. The AGC control mode is composed of basic power mode and regulating power mode. By setting different basic power mode and regulating power mode, different AGC control mode can be realized.

The basic power modes of units are divided into the following three categories:

1) AUTO: current actual power;

2) SCHE: defined by the generation planning curve of the plant/unit for the implementation of generation plan;

3) BASE: value given at that time; dispatchers can be required at any time to change basic power.

And there are four main types of regulating power modes:

1) $O$ (Off-regulated): in any case unit does not undertake regulating power; 
2) R (Regulated): when ACE exceeds the dead zone (value of ACE is more than 160), regulating power is required;

3) A (Assistant): in the sub-emergency or emergency regulation area (ACE value is greater than 240), regulating power is required;

4) E (Emergency): regulating power is assumed only in the emergency regulation area (ACE value is greater than 480).

The range of regulating power mode distribution is shown in Fig. 2. The AGC mode of coal-fired units generally chooses SCHEO or SCHER mode. The main reason for choosing SCHE mode is that thermal unit has system base load, and the load forecast is used to arrange corresponding generation schedule to follow the overall load change trend of the system, as shown in Fig.a 3.

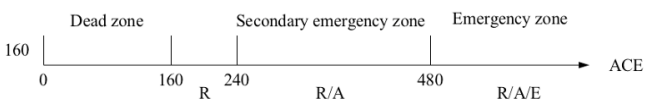

Fig. 2. Range of regulating power mode distribution

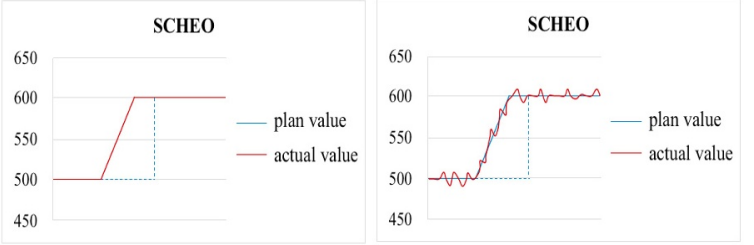

Fig. 3. SCHEO and SCHER mode

\subsection{Analysis of cost characteristics of thermal power units}

Cost, also known as total cost (TC), is the minimum total cost referring to a certain level of technology and factor prices in the production of a certain number of products, which increases with the increase in output. TC is the lowest cost under certain circumstances, and it is the cost under the optimal combination of various production factors, which includes fixed cost (FC) and variable cost (VC).

The average cost and marginal cost are two implied concepts. Average cost (AC) is the ratio of total cost and quantity of product; marginal cost (MC) is increased cost of producing 1 unit of product. For most industries, MC decreases with the increase of output when the output is small, and AC decreases also. As the output increases, $\mathrm{MC}$ decreases less, and even gradually increases with the increase of output. When MC increases to a certain extent, $\mathrm{AC}$ also begins to increase with the increase of output, as shown in Fig. 4. As can be seen from the graph, $\mathrm{MC}$ curve intersects $\mathrm{AC}$ curve and average variable cost (AVC) respectively, and the intersection point is the lowest point $B$ of AC curve and point $A$ of AVC curve. If enterprise quotes the price according to $\mathrm{MC}$, when output is lower than $Q_{A}$ or $Q_{B}, \mathrm{AC}$ is greater than MC. Thus enterprise can not make a profit at this time.

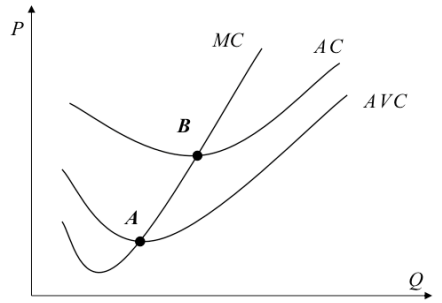

Fig. 4. Cost curve

\section{Unit Quotation Mechanism in Fujian Electric Power Spot Market}

In the electricity market environment, thermal power units need to make their own quotation strategies to maximize their profits based on market quotation rules and limits of rules. So, it is very important to study unit quotation mechanism in the Fujian spot market.

\subsection{Characteristics of day-ahead market quotation mechanism in Fujian}

Similar to the majority of domestic and foreign electricity market quotation rules, Electric Generators in Fujian electric power market use segmented, continuous and incremental way to quote. In the early days of operation of Fujian electric power market, only part of the proportional base quantity of units participating in spot bidding is taken as bidding space. It gradually adapts to the development of power market in a relatively stable way, but the price declared capacity of each unit in the day-ahead market is all capacity from minimum technical output of the unit to the rated active power. Each electric generator shall be quoted by capacity in a multi-section continuous way, with a provisional total of 5 sections. Among them, the initial contribution point of each quotation segment must be the contribution end point of the last quotation segment, and the quotation curve must be monotone non-decreasing with the increase of power. The quoted price of each market member shall not exceed the quoted price limit. The upper limit of the quoted price on the electricity day-ahead spot market shall be $130 \%$ of the benchmark price of coal-fired units, and the lower limit of the quoted price shall be $30 \%$ of the benchmark price. The output interval starting point and ending point should be integer value, and each output interval should not be less than 10MW.

In addition, according to the "Reform and Implementation Plan for deepening Formation Mechanism of tariff for coal-fired power generation in Fujian province" issued by Fujian Provincial Development and Reform Commission in January 2020 [3], the tariff for coal-fired generators has been changed to "Base price + fluctuation". The base price is 0.3932 yuan $/ \mathrm{kWh}$, and the coming-up range is not more than $10 \%$, where decreasing range is not more than $15 \%$ in principle. On these grounds, the quoted price range of coal-fired units is about 100.26 yuan/MWh - 562.28 yuan/MWh. Due to special situation of different units and the change and implementation of regulations, the 
actual scope may be different, but it can be observed that compared with Guangdong electricity market or foreign electricity market, quotation range of Fujian power dayahead spot market is smaller.

\subsection{Characteristics of real-time market and peak regulation ancillary service quotation mechanism in Fujian}

As power generation enterprises and power users who sign bilateral contracts have the same goal of pursuing economic benefits, they cannot meet real-time balance of the whole power from point of view of system operation. Therefore, the combination of long-term and short-term power trading contracts signed by market participants cannot completely meet requirements of power system safe and stable operation. Based on the actual problems of transmission congestion and forecast deviation, the system dispatching organization needs to carry out a series of operations in a certain period to ensure the realtime balance of power system operation.

According to the rules of Fujian electric power market, the real-time balanced downward pricing mechanism is similar to that of peak regulation ancillary services. In the auxiliary service of PR, the load ratio greater than or equal to the standard of PR baseline is the basic obligation of the units, and it can be called by electric power dispatching organization according to the system operation needs.

Table 3. Unit PR and balance mechanism benchmark

\begin{tabular}{|c|c|c|}
\hline $\begin{array}{c}\text { Unit } \\
\text { type }\end{array}$ & $\begin{array}{c}\text { Compensation } \\
\text { benchmark for paid } \\
\text { PR (load rate) }\end{array}$ & $\begin{array}{c}\text { Real-time } \\
\text { balancing } \\
\text { mechanism } \\
\text { benchmark (load } \\
\text { rate) }\end{array}$ \\
\hline $\begin{array}{c}\text { Thermal } \\
\text { power } \\
\text { unit }\end{array}$ & $60 \%$ & $60 \%$ \\
\hline $\begin{array}{c}\text { Nuclear } \\
\text { power } \\
\text { unit }\end{array}$ & $75 \%$ & $75 \%$ \\
\hline
\end{tabular}

Power Generation Enterprises shall take the unit's load rate of compensated PR benchmark as the starting point and quote the price in the form of a capacity reduction ratio. A quoted price range should be $5 \%$ of capacity ratio of the reduction units, and the price should increase with the increase of peak shaving depth. The upper limit of the quoted price corresponding to the reduction capacity ratio is shown in Table 4 . The power plants participating in the bidding shall quote the unit price, and the downgrading power of each unit shall be reported to the minimum technical output. The unit's settlement fee of paid peak regulation and reduction service is the accumulation of product of actual response power and the winning bid price in each section.
Table 4. Benchmark of quoted price corresponding to the reduction capacity ratio

\begin{tabular}{|c|c|}
\hline $\begin{array}{c}\text { Ratio of reduction } \\
\text { capacity }\end{array}$ & $\begin{array}{c}\text { Declared price } \\
\text { (yuan/MWh) }\end{array}$ \\
\hline$(0 \%, 5 \%]$ & $\leqslant 100$ \\
\hline$(5 \%, 10 \%]$ & $\leqslant 200$ \\
\hline$(10 \%, 15 \%]$ & $\leqslant 400$ \\
\hline$(15 \%, 20 \%]$ & $\leqslant 500$ \\
\hline $20 \%$ and above & $\leqslant 600$ \\
\hline
\end{tabular}

\section{Research on Bidding Strategies of Thermal Power Units in Fujian Electricity Spot Market}

\subsection{Research status of bidding strategies for thermal power units}

With the deepening and development of the reform of power market, new market trading models have been established and gradually improved. In view of different power markets in different countries and even the same market in various stages, research work on bidding strategies has obtained the rapid development. In recent years, domestic and foreign scholars have done a lot of work on the bidding strategies of power plants. Reviews of previous research work in the field of research methods has been made in the literature [4,5]. At present, ideas and methods of constructing competitive bidding strategies by researchers at home and abroad can be divided into three categories: the methods based on cost analysis, the methods for forecasting market electricity price, and the methods based on game theory.

\subsubsection{Bidding strategies based on cost analysis}

The goal of power plants participating in electricity trading is to realize the profit maximization, and the revenue from bidding and cost of producing electricity are the core elements that determine the profit level of power plants. Therefore, cost analysis is the premise and basis of bidding decision-making for power plants. The method based on cost analysis is the most common method used by power plants to construct bidding strategies in the domestic electricity market at present. The main idea is to determine the actual generation cost of power plants themselves, plus a certain profit margin as an offer. Theoretically speaking, in an ideal market, the final bidding price will form a Nash Equilibrium (NE), and the power generation enterprises will bid with their own MC. The key point of the bidding strategy based on cost analysis is the need for enterprises to have an accurate understanding of their own generation costs, including $\mathrm{FC}, \mathrm{VC}$ and so on.

The bidding strategy based on cost analysis is analyzed in detail in reference [6-8]. Among them, 
reference [6] puts forward the method of dynamic cost analysis of thermal power plant according to the need of power plant bidding, and forms cost analysis model through statistical analysis; In reference [7], a cost model reflecting the degree of wear of power generating equipment is constructed by combining the mechanical wear of electric generator with the start-up, stop-down and ramp-up rate of thermal power units. The strategy put forward in reference [8] is to strive for the network capacity on the premise that the market price is higher than $\mathrm{VC}$, and to draw a profit curve to determine the price quickly.

The bidding strategy based on cost analysis has the advantages of simple principle and easy operation. It is a relatively conservative market strategy and can lock in a certain rate of return without losing money, so it is very suitable for the initial electricity market bidding experience of power producers. The emphasis is to recognize the characteristics of spot market, analyze the cost factors related to the competitive load in the spot market, and take a conservative approach to deal with market changes. However, this method does not take into account the bidding situation of other manufacturers and real-time fluctuation of load and electricity price, so it is difficult to achieve the goal of profit maximization.

\subsubsection{Bidding strategies based on market clearing prices}

The method of forecasting electricity price is the simplest method in the study of bidding strategy: as long as the electricity price of each trading period on the next day is predicted, and the bidding price is lower than the predicted value according to market rules, power generation companies have the opportunity to make a profit. This method assumes that bidding behavior of power plants is not enough to influence the market price, so it is suitable for small power plants to make bidding strategy.

The market clearing price is the actual reflection of the quoted price result in the spot market and directly affects the market interest of market subjects, so how to forecast the clearing price of spot market of electric power accurately and effectively is of great significance to the decision-making of market participants and the grasp of market laws.

At present, there are two main directions in the research of market clearing price forecasting:

1) Indirect forecasting method through market simulation, which makes use of the mechanism of power market price formed by supply and demand relation and the behavior of market subjects, to get the market clearing price by simulating market transactions and forecasting the power supply and demand in the market. This method simulates the actual market situation by considering the power system conditions and constraints, and can get more practical and effective clearing price information. In order to get accurate prediction result of market clearing price by market simulation, the basic data of power market must be fully detailed and accurate. But at present, the data scale of power market is huge, the connection is complex, and the accurate prediction of power system load is still a problem to be studied, so the indirect prediction method of market simulation is difficult to be applied to the actual production decision.

2) Direct forecasting method through data analysis, which uses a lot of data analysis to mine the market clearing price's own law and the data connection with other related factors and makes mathematical modeling to obtain market clearing price forecasting model. Different mathematical modeling methods mainly include time series analysis, multiple regression, artificial neural network, wavelet analysis, support vector machine, combination method and so on. In the previous studies, literature [9-11] used BP neural network model to predict system MC; literature [12] used dynamic fitting and translation function model to predict the price based on traditional time series method; and literature [13] applied a Generalized Autoregressive Conditional Heteroskedastic $(\mathrm{GARCH})$ model to predict electricity prices in the day-ahead market at various periods.

The method of constructing bidding strategy by forecasting market electricity price is the most basic and common method in the field of bidding strategy research, which can be combined with traditional unit commitment model. This method is conducive to constructing a multi-period bidding strategy, but it does not take into account the influence of bidding behavior of power producer itself on market price.

\subsubsection{Game theory based approach}

The game theory mainly studies how two or more conflicting individuals make their optimal decision under the condition of interaction, which can be applied to the bidding decision of generation enterprises in the market. Reference [14] introduces the modeling and solving process of game theory, and briefly expounds the application of game theory in power market. The idea of game theory is to establish a game model and a supplydemand relationship model according to the transaction behavior of electricity market, in order to find the equilibrium point of the model, which is the best bidding strategy of each generation enterprise. So, game Theory based analysis is essentially a special form of mathematical optimization.

The basic idea of applying the game theory to construct the bidding strategy of power plants can be divided into two kinds: one is to regard the bidding problem of power plants as the game behavior between bidders and market, thus a zero-sum two-person mixed game model is used to describe the bidding strategy of power plants by solving the equilibrium solution of the game model [15]; the other is to describe the competition of the competitors in the electricity market as a noncooperative game problem, and to solve its $\mathrm{NE}$ as a bidding strategy.

In addition, the matrix game model is also applied to the bidding strategy of power plants. In this method, the alternative bidding strategies are represented as discrete quantities, and the equilibrium strategies are solved by 
constructing the profit matrix of different combination of bidding strategies.

In principle, the equilibrium points of these models correspond to the optimal bidding strategies of generation companies. As many simplified assumptions are applied in the models, the equilibrium strategy used as the bidding strategy of power plants is often different from the actual situation [16]. However, these models are of great theoretical significance for power producers to analyze the bidding behavior of other competitors, and for regulators to analyze the potential market power and perfect the market rules.

\subsection{Bidding strategy of thermal power units in Fujian Power Spot Market}

The power market in Fujian is currently in the exploratory stage, and the main participants are coal power units. Therefore, this paper mainly analyzes the bidding strategy of the day-ahead wholesale market of coal power units. At the initial stage of operation, the Fujian power spot market adopts the pricing mechanism of systematic unified marginal clearing price, that is, the quotation of the last unit in the target within the trading period that satisfies the balance of power and quantity of the system is taken as the marginal price of the market during that period. In the early stage of operation, the operation data of Fujian power spot market is less, so market members are lack of analysis data, and the bidding strategy is not stable, so it is not suitable to adopt bidding strategies such as predicting price and predicting the opponent's behaviors. In addition, the coal burning cost of different groups of coal generating units is different, because the cost of coal generating units is greatly affected by the coal price. And the transportation cost is different due to different geographical locations. Therefore, coal generating units in the power market in Fujian should adopt the bidding strategy based on the generation cost according to their own cost situation.

Based on the quotation method of MC analysis, MC under different outputs is first calculated and fitted to form cost curve of power generation. Combined with cost curve and reasonable profit, the bidding price is formed. The real-time online monitoring system of coal consumption can get the output and coal consumption in different time periods, which can be taken as independent variables and dependent variables respectively. After collecting enough data, the total coal consumption curve can be fitted into a polynomial function, as is shown below, where $P$ represents the unit output. TC calculates in:

$$
F(P)=C_{n} * P^{n}+C_{n-1} * P^{n-1}+\cdots+C_{0}
$$

And AC calculates in:

$$
F_{\text {avg }}(P)=\frac{F(P)}{P}=C_{n} * P^{n-1}+C_{n-1} * P^{n-2}+\cdots+\frac{C_{0}}{P}
$$

And MC calculates in

$$
F_{\text {marg in }}(P)=\frac{d F(P)}{d P}=n * C_{n} * P^{n-1}+(n-1) * C_{n-1} * P^{n-2}+\cdots+C_{1}
$$

Usually, if $n=2$ or $n=3$, a better fitting effect can be achieved.

Bidding strategy based on $\mathrm{MC}$ is shown in the figure below, where AC represents $F_{\text {avg }}$, MC represents $F_{\text {margin }}$, Offer Curve represents the multi-segment bidding curve, and $P_{\min }$ represents the minimum output.

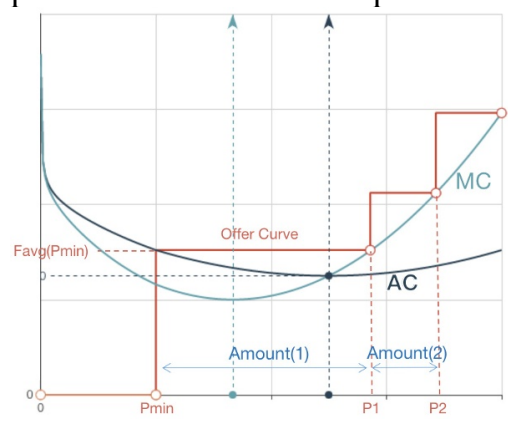

Fig. 5. Bidding strategy based on $\mathrm{MC}$

Therefore, the bidding strategy is:

1) Take the output $P_{\min }$ of Min Power to get $F_{l}$ :

$$
F_{1}=F_{a v g}\left(P_{\min }\right)
$$

2) Make:

$$
F_{m \arg i n}\left(P_{1}\right)=F_{1}
$$

to obtain two solutions: $P_{1}$ and $P_{1}{ }^{\prime}$, and $P_{1}>P_{l}{ }^{\prime}$; then the first declared power Amount(1) is:

$$
\text { Amount }(1)=P_{1}-P_{\min }
$$

And the first declared price price (1) is:

$$
\text { Price }(1)=F_{m \arg i n}\left(P_{\min }+\text { Amount }(1)\right)
$$

3) For quotation of remaining $M-1$ sections, the rest of declared power quantity is $P_{\max }-P_{1}$, which can be distributed according to risk preference of units or equally distributed. Take the average distribution as an example - declared power quantity of each section $A$ is:

$$
A=\frac{P_{\max }-P_{1}}{M-1}
$$

So declared power quantity of the second paragraph is:

$$
\text { Amount(2) }=A
$$

Price is:

$$
\text { Price }(2)=F_{m \arg i n}\left(P_{\min }+\text { Amount }(1)+\text { Amount }(2)\right)
$$

And the quotation in the M-th paragraph is:

$$
\operatorname{Amount}(M)=A
$$

$\operatorname{Pr} i c e(M)=F_{m \text { argin }}\left(P_{\text {min }}+(m-1) * A\right)=F_{\text {margin }}\left(P_{\text {max }}\right)$

4) The final quotation submitted is:

Table 5. Final price quotation submission

\begin{tabular}{|c|c|c|c|c|}
\hline ID & $\begin{array}{c}\text { Start } \\
\text { power }\end{array}$ & $\begin{array}{c}\text { End } \\
\text { power }\end{array}$ & Amount & Price \\
\hline Band 1 & $P_{\min }$ & $P_{1}$ & $P_{\min -} P_{I}$ & Price(1) \\
\hline
\end{tabular}




\begin{tabular}{|c|c|c|c|c|}
\hline Band 2 & $P_{I}$ & $P_{I}+A$ & $A$ & Price(2) \\
\hline$\ldots \ldots$ & $\ldots \ldots$ & $\ldots \ldots$ & $\ldots \ldots$ & $\ldots \ldots$. \\
\hline Band $\mathrm{M}$ & $P_{\max -A}$ & $P_{\max }$ & $A$ & $\operatorname{Price}(M)$ \\
\hline
\end{tabular}

\section{Conclusion}

In the electric power market environment, merits and disadvantages of bidding schemes of thermal power units are directly related to their interests. The bidding decisions of power plants are not only affected by economic factors, but also restricted by the unique technical factors of power system and generator units. Based on the summary and review of literature at home and abroad, this paper analyzes basic technical characteristics of thermal power units, in-depth analyzes cost calculation. Proceeded from aspect of quotation, the paper analyzes bidding mechanisms of units in Fujian electric day-ahead market, real-time balance market and ancillary services market. On account of summary of bidding strategies of thermal power units in participating in the research status of power market, the paper divided the bidding strategies into three methods, including cost analysis, market clearing price prediction and game theory. Then the unit bidding strategy suitable for Fujian spot market is proposed.

In the actual decision-making process of power generation enterprises, it is necessary to establish a unified revenue model to pursue the maximization of total revenue according to the quotation mechanism, clearing and settlement rules of multiple markets in which they are currently located. A multi-objective approach can also be adopted to meet the interests of the group, social policies, environmental protection and other requirements. At the same time, when choosing decision methods based on cost analysis, market clearing price forecast, competitor behavior estimation, game theory and so on, it is necessary to select a combination of various methods according to the data scale and data quality that the enterprise currently possesses to make analysis and decision.

\section{References}

1. General Office of NDRC, Comprehensive Department of NEA. Opinions on deepening the construction pilot work of power spot market [EB/OL].

[2020-02-20]. https://www.ndrc.gov.cn/xxgk/zcfb/ghxwj/201908/t 20190807_960970.html.

2. Liu J, Zeng D, Tian L, et al. Control strategy for operating flexibility of coal-fired power plants in alternate electrical power systems[J]. Proceedings of the CSEE, 2015, 35(21): 5385-5394.

3. Fujian Provincial Development and Reform Commission. Reform and implementation plan for deepening formation mechanism of tariff for coalfired power generation in Fujian province [EB/OL]. http://fgw.fujian.gov.cn/zfxxgkzl/zfxxgkml/yzdgkdq txx/202001/t20200108_5176301.htm.

4. David A K, Wen F. Strategic bidding in competitive electricity markets: a literature survey[C]//2000 Power Engineering Society Summer Meeting (Cat. No. 00CH37134). IEEE, 2000, 4: 2168-2173.

5. Bing L, Xiuli W, Ying G, et al. Analysis on bidding strategy of independent power producer in daysahead market $[\mathrm{J}][\mathrm{J}]$. Automation of Electric Power Systems, 2002, 26(24): 8-14.

6. Fansheng L, Lijie X, Wei W. Analysis of dynamic cost in power plant operation for bidding[J]. POWER SYSTEM TECHNOLOGY-BEIJING-, 2001, 25(7): 44-47.

7. Gallestey E, Stothert A, Antoine M, et al. Model predictive control and the optimization of power plant load while considering lifetime consumption[J]. IEEE Transactions on Power Systems, 2002, 17(1): 186-191.

8. Jianping Z, Hao Z. Preliminary study on bidding strategy for electricity market[J]. Electric Power, 2001(03):9-11

9. Li Y, Jiaju Q, Daozhuo J. BPN based day-ahead unconstrained market clearing price forecasting model[J]. Automation of Electric Power Systems, 2001, 25(19): 11-14.

10. Li C, Guo Z. Short-term system marginal price forecasting with hybrid module[C]/Proceedings. International Conference on Power System Technology. IEEE, 2002, 4: 2426-2430.

11. Wang A, Ramsay B. Prediction of system marginal price in the UK Power Pool using neural networks[C]/Proceedings of International Conference on Neural Networks (ICNN'97). IEEE, 1997, 4: 2116-2120.

12. Nogales F J, Contreras J, Conejo A J, et al. Forecasting next-day electricity prices by time series models[J]. IEEE Transactions on power systems, 2002, 17(2): 342-348.

13. Garcia R C, Contreras J, Van Akkeren M, et al. A GARCH forecasting model to predict day-ahead electricity prices[J]. IEEE transactions on power systems, 2005, 20(2): 867-874.

14. Diao Q, Lin J, Ni Y, et al. Game theory and its applications in power markets[J]. Automation of Electric Power Systems, 2001, 25(1): 19-23.

15. Shang J C, Huang Y H, Zhang W C, et al. A model and algorithm of game theory based bidding strategy for an independent power provider[J]. Automat Electric Power Syst, 2002, 26(9): 12-5.

16. Niu H, Baldick R, Zhu G. Supply function equilibrium bidding strategies with fixed forward contracts[J]. IEEE Transactions on power systems, 2005, 20(4): 1859-1867. 